\title{
Moderate Carnitine Depletion and Long-Chain Fatty Acid Oxidation, Exercise Capacity, and Nitrogen Balance in the Rat
}

\author{
OLLI J. HEINONEN AND JUKKA TAKALA \\ Central Laboratory, Department of Clinical Chemistry, Turku University Hospital, \\ Kiinamyllynkatu 4-8, FIN-20520 Turku /O.H.]; Paavo Nurmi Center, Sports Medical Research \\ Unit and Department of Physiology, University of Turku, Turku, Finland /O.H.|; and Critical \\ Care Research Program, Department of Intensive Care, Kuopio University Hospital, \\ FIN-70210 Kuopio, Finland |J.T.|
} \begin{abstract}
Carnitine plays a central role in lipid metabolism by
transporting long-chain fatty acids into the mitochondria for $\beta$-oxidation. Reduction of carnitine concentration does not automatically imply that functional carnitine deficiency exists with direct consequences on energy metabolism. In our experimental model, we reduced tissue concentrations of carnitine to levels that are comparable to those in patients with various metabolic disorders with secondary carnitine deficiency and did a study on the in vivo effects of moderate carnitine depletion on palmitate oxidation, exercise capacity, and nitrogen balance. Thirty rats were divided into a carnitine-depleted group (group I) and pair-fed controls (group II). Carnitine depletion resulting in a $48 \%$ reduction of tissue carnitine concentrations was induced by feeding ad libitum a carnitine-free oral diet consisting of parenteral nutrition solutions. Palmitate oxidation was
\end{abstract}

measured by collecting expired ${ }^{14} \mathrm{CO}_{2}$ after an intraperitoneal injection of $\left[1-{ }^{14} \mathrm{C}\right]$ palmitate, and exercise capacity was determined by having the rats swim to exhaustion. Despite the $48 \%$ depletion of carnitine in serum, muscle, and liver, there were no differences in cumulative palmitate oxidation in $3 \mathrm{~h}$ (group I, $40 \pm 7 \%$; group II, $37 \pm 9 \%$ of injected activity), swimming time to exhaustion (group I, $8.1 \pm 2.8 \mathrm{~h}$; group II, $7.7 \pm 3.6 \mathrm{~h}$ ), or nitrogen balance (group I, $1.1 \pm 0.5 \mathrm{~g}$ of nitrogen $/ \mathrm{kg} / \mathrm{d}$; group II, $1.2 \pm 0.5 \mathrm{~g}$ of nitrogen $/ \mathrm{kg} / \mathrm{d}$ ). We conclude that carnitine depletion of $48 \%$ has no effect on palmitate oxidation, exercise capacity, or nitrogen balance in the rats studied. (Pediatr Res 36: 288-292, 1994)

\section{Abbreviations}

TPN, total parenteral nutrition
Carnitine plays a central role in lipid metabolism. Its main function is to transport long-chain fatty acids from the cytosol into the mitochondrial matrix for $\beta$-oxidation (1). Without carnitine, long-chain fatty acids are unable to penetrate the mitochondrial membrane. Carnitine also modulates CoA metabolism and ketogenesis $(2,3)$. FFA are important source of energy during fasting and also in the resting muscles (4). During low-intensity exercise the utilization of fatty acids by muscles is increased, and during prolonged exercise fatty acid oxidation eventually becomes the major energy source for muscles (4). Carnitine also improves nitrogen metabolism by stimulation of the oxidation of branched-chain amino acids in the

Received July 7, 1992; accepted March 29, 1994.

Correspondence and reprint requests: Dr. Olli J. Heinonen, Central Laboratory, Department of Clinical Chemistry, Turku University Hospital, Kiinamyllynkatu 4-8, FIN-20520 Turku, Finland.

Supported in part by grants from the Ministry of Education of Finland, The Medical Council of the Academy of Finland, the Paulo Foundation, and the Turku University Foundation. muscle (5) and improves nitrogen balance during experimental TPN $(6,7)$.

L-Carnitine has been described in the literature as a "conditionally essential nutrient." Most often, preterm individuals, term infants, and patients fed entirely parenterally are suggested to require exogenous carnitine (8).

Primary carnitine deficiency is caused by a defect of carnitine transport into the cells and inability to establish a concentration gradient over the cell membrane (9-11). Carnitine deficiency manifests in childhood as recurrent attacks of hepatic encephalopathy or progressive cardiomyopathy, muscle weakness, and lipid storage myopathy (12). Concentration of carnitine in the muscle is extremely low $(9,12)$ and the utilization of long-chain fatty acids is impaired (13). Carnitine supplementation to a patient with low carnitine has stimulated fat oxidation in muscle homogenate (13), and muscle fat oxidation in vitro is reported to correlate with carnitine concentration (14). 
Although primary carnitine deficiency inevitably impairs fatty acid oxidation, the metabolic and physiologic consequences of moderately reduced tissue concentrations of carnitine in other clinical conditions have not been established. Low tissue carnitine concentration as a secondary phenomenon has been found in many metabolic disorders, e.g. defects in $\beta$-oxidation, citric acid cycle, respiratory chain, organic acid metabolism, and amino acid metabolism $(9,15-17)$. Furthermore, drugs like valproate, pivampicillin, and pivmecillinam, which induce excessive urinary loss of carnitine $(15,18)$, lead to low tissue concentrations of carnitine. The patients with secondary carnitine deficiency have moderately decreased concentrations of carnitine, but the effect of moderately decreased tissue carnitine on lipid metabolism in vivo is unknown (19).

We have demonstrated that tissue concentrations of carnitine decrease by $50 \%$ after prolonged oral feeding of carnitine-free parenteral nutrition solutions in rats (20), presumably because the endogenous synthesis of carnitine is insufficient for the maintenance of normal tissue carnitine concentrations. In this depletion model, tissue carnitine concentrations are reduced by approximately $50 \%$, which is comparable to the reductions commonly observed in secondary carnitine deficiency (21).

The aim of this study was to assess the effects of this $50 \%$ reduction of tissue carnitine concentrations on the oxidation of palmitate in vivo, exercise capacity, and nitrogen balance in rats.

\section{METHODS}

This study was approved by the Ethics Committee of Turku University.

Animals. Thirty young male Wistar rats (aged 4-5 wk, weight $130-170 \mathrm{~g}$ ) were randomly assigned to two groups. The rats were housed in individual cages under controlled conditions (lights on from 0700 to $1900 \mathrm{~h}$, temperature 22 $\pm 1{ }^{\circ} \mathrm{C}$, and $60 \%$ relative humidity) and were weighed weekly after an 8-h fast.

Diet. Carnitine depletion was induced in 15 rats (group I) by feeding ad libitum an oral diet consisting of carnitine-free TPN solutions. Another group of 15 rats (group II) was pair-fed a standard laboratory pellet diet (Ewos R3, Ewos Company, Södertälje, Sweden). The measured carnitine content of the normal pellet diet was $60 \mathrm{nmol} / \mathrm{g}$. The experimental carnitine-free diet consisted of parenteral nutrition infusates given orally. This diet contained $403 \mathrm{~kJ}(96.5 \mathrm{kcal})$ of energy, $0.7 \mathrm{~g}$ of nitrogen, and $5.3 \mathrm{~g}$ of amino acids per $100 \mathrm{~mL}$ and it has been described in detail (20). The diet was obtained by mixing an $8.6 \%$ amino acid solution (Levamin normo, Huhtamäki OY Leiras, Turku, Finland) with $50 \%$ glucose solution (Glucos 50\%, Huhtamäki OY Leiras) and 20\% fat emulsion (Emulsan 20\%, Huhtamäki OY Leiras) (Table 1). Electrolytes, minerals, trace elements, and vitamins were added. The relative contents of protein and energy were equal in the experimental carnitine-free diet and the
Table 1. Amino acid and energy content of the carnitine-free experimental diet

Content $/ 100 \mathrm{~mL}$ diet

\begin{tabular}{lr} 
Amino acids & \\
Isoleucine & $4.3 \mathrm{~g}$ \\
Leucine & $6.7 \mathrm{~g}$ \\
Lysine & $3.8 \mathrm{~g}$ \\
Methionine & $2.8 \mathrm{~g}$ \\
Phenylalanine & $2.9 \mathrm{~g}$ \\
Threonine & $2.1 \mathrm{~g}$ \\
Tryptophane & $0.8 \mathrm{~g}$ \\
Valine & $3.7 \mathrm{~g}$ \\
Arginine & $4.3 \mathrm{~g}$ \\
Histidine & $1.5 \mathrm{~g}$ \\
Alanine & $3.7 \mathrm{~g}$ \\
Cysteine/cystine & $12.2 \mathrm{mg}$ \\
Proline & $5.8 \mathrm{~g}$ \\
Aminoacetate & $4.9 \mathrm{~g}$ \\
Serine & $3.1 \mathrm{~g}$ \\
Lipids & \\
Soya oil & $2.5 \mathrm{~g}$ \\
Egg lecithin & $0.15 \mathrm{~g}$ \\
Glucose & \\
50\% glucose & $25 \mathrm{~mL}$ \\
\hline
\end{tabular}

pellet diet. The pair-feeding procedure excludes any effect of quantitative differences in the intake of energy and protein. The pair-feeding continued for $7 \mathrm{wk}$. This feeding protocol results in a 50\% reduction of tissue carnitine concentrations in experimental animals, whereas pair-fed controls have normal values $(20,22)$. Both groups had five controls for the measurement of tissue carnitine concentrations. After $6 \mathrm{wk}$ of dietary manipulation, carnitine in serum, gastrocnemius and soleus muscles, and liver was analyzed in these rats to confirm the carnitine depletion.

Carnitine analysis. Serum and urine samples were analyzed as such, whereas tissue carnitine analyses were performed on the neutralized supernatant after perchloric acid precipitation of the tissue homogenate. Free and total acid-soluble carnitine were measured with the radioenzymatic assay (23) with minor modifications. Tris buffer was replaced by $0.1 \mathrm{M} \mathrm{KCl}, 1 \mathrm{mM}$ EDTA solution (pH 7.0) for free carnitine determination or $0.1 \mathrm{M} \mathrm{KOH,}$ $1 \mathrm{mM}$ EDTA solution ( $\mathrm{pH} 12.5$ ) for total acid-soluble carnitine measurement. The hydrolysis, neutralization, and separation of labeled acetylcarnitine from the $\left[1-{ }^{14} \mathrm{C}\right]$ acetyl-CoA by Dowex 2-X8 mesh $100-200$ (Clform) anion-exchange resin (Bio-Rad Laboratories, Richmond, CA) were done according the original method of Cederblad and Lindstedt (24). Total acid-soluble carnitine was determined after alkaline hydrolysis and free carnitine was measured directly. Acylcarnitine was calculated by subtracting free carnitine from the total. Normal values of tissue carnitine concentrations from our laboratory have been previously reported (22).

Palmitate oxidation in vivo. During the 7 th wk of the experiment, palmitate oxidation was measured after an 8-h fast by placing each rat into an individual Plexiglas metabolic cage for a period of $3 \mathrm{~h}$. A constant flow of $1000 \mathrm{~mL}$ 
of room air per min was vacuumed through the cage. After $30 \mathrm{~min}$ of adaptation, a single dose of $2.0 \mu \mathrm{Ci}$ of $\left[1-{ }^{14} \mathrm{C}\right]$ palmitate per $100 \mathrm{~g}$ of body weight was given by intraperitoneal injection. Radioactive palmitate $(0.1$ $\mathrm{mCi} / \mathrm{mL}$ with a sp act of $58.0 \mathrm{mCi} / \mathrm{mmol}$; New England Nuclear, Boston, MA) was complexed to $0.2 \mathrm{mM}$ defatted BSA in $154 \mathrm{mM} \mathrm{NaCl}$. The exact dose injected was determined by weighing the syringe before and after the injection. The air flow from the cage was led through three vials containing $5.0 \mathrm{~mL}$ of hyamine hydroxide. The hyamine vials were replaced at 15 -min intervals. The ${ }^{14} \mathrm{CO}_{2}$ activity was measured after mixing a $1-\mathrm{mL}$ aliquot of the hyamine hydroxide with $10 \mathrm{~mL}$ of scintillation counting solution (Carboluma, Lumac, Schaesberg, The Netherlands), and counted with an LKB 1219 Rackbeta scintillation counter (Wallac, Turku, Finland). The total activity consisted of the sum of the activities in the three vials.

Exercise capacity. Exercise capacity was measured later in the 7th week by letting the rats swim to exhaustion (25). Each rat was allowed to swim separately in a Plexiglas tank where the water temperature was adjusted to $35-36^{\circ} \mathrm{C}$. Small weights that were $2.0 \%$ of the rat's body weight were tied to the tail of the animal to reduce the swimming time and variability between animals.

Nitrogen balance. The total nitrogen was measured in 24-h urine collections by chemiluminescence (26) by an Antek Auto-Analyzer 703C (Antek Instruments Inc., Houston, TX). Nitrogen balance was calculated as the difference between dietary nitrogen according manufacturer's specification and measured urinary nitrogen.

Study design. When studying palmitate oxidation in vivo, exercise capacity, and nitrogen balance, each carnitine-depleted animal was always simultaneously tested with its pair-fed control (Table 2).

Statistical analysis. The results are expressed as mean \pm SD. Comparison of tissue concentrations of carnitine were made by the $t$ test for matched pairs. Differences in palmitate oxidation in vivo were analyzed by analysis of variance with repeated measures designed for matched pairs with one grouping factor (carnitine treatment) and one within factor (time). Otherwise, analysis of variance for matched pairs with one grouping factor (carnitine treatment) and covariate (weight) was used. The normality of the distributions and equality of group variances were tested. A $p$ value of less than 0.05 was considered significant.

\section{RESULTS}

Carnitine depletion model. The feeding protocol resulted in normal carnitine concentration in serum, muscle, and liver in the pair-fed controls, whereas a decrease of tissue carnitine to $50-52 \%$ of normal was observed in the depleted group (Table 3 ), reproducing our previous results with the same model (20). The mean daily consumption of the experimental carnitine-free liquid diet was $75 \pm 5,101$ $\pm 6,84 \pm 14,78 \pm 15,81 \pm 12$, and $91 \pm 9 \mathrm{~mL}$ during $\mathrm{wk}$ $1,2,3,4,5$, and 6 , respectively. The corresponding mean daily intake of energy was $302 \pm 20,409 \pm 23,337 \pm 58$, $314 \pm 62,325 \pm 47$, and $367 \pm 35 \mathrm{~kJ}$ and that of nitrogen was $0.5 \pm 0.03,0.7 \pm 0.004,0.6 \pm 0.1,0.5 \pm 0.1,0.6 \pm$ 0.08 and $0.6 \pm 0.06 \mathrm{~g}$ during wk $1-6$. Because of the pair-feeding, the intakes of protein and energy were identical in the normal controls, and fulfilled the requirements for protein and energy of the laboratory rat in both groups studied. The initial mean weights of the rats were similar $(158 \pm 16$ and $159 \pm 16 \mathrm{~g}$ ), but after $6 \mathrm{wk}$ the mean weight in the carnitine-depleted group was $301 \pm 24 \mathrm{~g}$ and that in the control group was $351 \pm 27 \mathrm{~g}(p<0.01)$.

Palmitate oxidation. The cumulative oxidation of palmitate in $3 \mathrm{~h}$ was similar in the carnitine-depleted rats $(40.4$ $\pm 7.3 \%)$ and the pair-fed controls $(37.1 \pm 9.3 \%)$ (Fig. 1). The ${ }^{14} \mathrm{CO}_{2}$ activity in the third hyamine vial was less than $3 \%$ of the sum of the three-vial collecting system, confirming good trapping efficiency.

Exercise capacity. Exercise capacity, measured as swimming time to exhaustion, was similar in the carnitine-depleted $(8.1 \pm 2.8 \mathrm{~h})$ and the pair-fed rats $(7.7 \pm$ $3.6 \mathrm{~h})$. No relation was found between body weight and swimming time.

Nitrogen balance. All the animals were in positive nitrogen balance. Carnitine depletion had no effect on nitrogen balance. Nitrogen balance in the depleted rats was $1.1 \pm 0.5 \mathrm{~g}$ of nitrogen $/ \mathrm{kg} / \mathrm{d}$ and $1.2 \pm 0.5 \mathrm{~g}$ of nitrogen/ $\mathrm{kg} / \mathrm{d}$ in the controls (NS).

\section{DISCUSSION}

This is the first study on the effects of diet-induced carnitine depletion on palmitate oxidation and exercise capacity in vivo. Previous experimental models of carnitine depletion interfere not only with carnitine but also with other metabolic functions, because they have been induced by deficiency of one of the essential components of carnitine biosynthesis-methionine, lysine, ascorbic acid, iron, or pyridoxal phosphate (20)-or by repeated intraperitoneal injections of the unphysiologic $\mathrm{D}$-form of carnitine (27). The advantage of our approach is the exclusion of carnitine without affecting the intakes of the essential components of endogenous carnitine synthesis (20). The carnitine depletion model induces carnitine

Table 2. Study design

\begin{tabular}{|c|c|c|c|c|c|c|c|}
\hline \multicolumn{8}{|c|}{ Carnitine-free oral diet, pair-feeding with normal pellet diet } \\
\hline \multirow{3}{*}{$\begin{array}{l}\text { Wk } 1-6 \\
\text { (d 1-42) }\end{array}$} & \multicolumn{7}{|c|}{ Wk 7} \\
\hline & d 43 & d 44 & d 45 & d 46 & d 47 & d 48 & d 49 \\
\hline & Weighing & $\begin{array}{l}\text { Nitrogen balance } \\
\text { analysis }\end{array}$ & $\begin{array}{l}\text { Carnitine analysis } \\
\text { (rats } 1-10)\end{array}$ & $\begin{array}{l}\text { Palmitate oxidation } \\
\text { measurement } \\
\text { (rats } 11-2(0)\end{array}$ & $\begin{array}{l}\text { Palmitate oxidation } \\
\text { measurement } \\
\text { (rats 21-30) }\end{array}$ & $\begin{array}{l}\text { Exercise capacity } \\
\text { measurement } \\
\text { (rats } 11-2(0)\end{array}$ & $\begin{array}{c}\text { Exercise capacity } \\
\text { measurement } \\
\text { (rats 21-30) }\end{array}$ \\
\hline
\end{tabular}


Table 3. Tissue carnitine concentrations in camitine-depleted rats (group $I, n=5$ ) and their pair-fed controls (group II, $n$ $=5)$ and normal values of ad libitum fed rats with the same age as in this study*

\begin{tabular}{lccc}
\hline & Group I & Group II & Normal values $\|$ \\
\hline $\begin{array}{l}\text { Serum carnitine } \\
(\mu \mathrm{mol} / \mathrm{L})\end{array}$ & & & \\
$\quad$ & & & \\
Total & $25.8 \pm 7.7 \dagger$ & $85.9 \pm 6.4$ & $95.0 \pm 13.8$ \\
Free & $21.0 \pm 7.6 \dagger$ & $71.7 \pm 6.1$ & $80.2 \pm 12.7$ \\
Acyl & $4.8 \pm 1.9 \dagger$ & $14.2 \pm 3.2$ & $14.7 \pm 3.3$ \\
Muscle carnitine & & & \\
$\quad(\mu$ mol/g dry wt) & & & \\
Total & $2.3 \pm 0.4 \dagger$ & $4.3 \pm 0.1$ & $4.4 \pm 0.8$ \\
Free & $2.0 \pm 0.3 \dagger$ & $3.8 \pm 0.1$ & $3.8 \pm 0.6$ \\
Acyl & $0.35 \pm 0.20 \ddagger$ & $0.58 \pm 0.06$ & $0.62 \pm 0.17$ \\
Liver carnitine & & & \\
$\quad(\mu$ mol/g dry wt) & & & \\
Total & $0.75 \pm 0.13 \S$ & $1.41 \pm 0.14$ & $1.10 \pm 0.19$ \\
Free & $0.68 \pm 0.11 \dagger$ & $1.22 \pm 0.06$ & $1.00 \pm 0.17$ \\
Acyl & $0.07 \pm 0.01 \ddagger$ & $0.18 \pm 0.08$ & $0.08 \pm 0.03$ \\
\hline
\end{tabular}

* All data are presented as mean \pm SD. Difference between groups I and II, $t$ test for matched pairs, is shown by symbols.

$+p<0.001$

$\ddagger p<0.05$.

$\S p<0.01$.

|i Data adapted from Ref. 20.

depletion of $50 \%$ or more of normal values in serum, muscle, and liver (20), and the reproducibility of the model was confirmed in this study. It is important that the effects of lack of carnitine are accentuated in young, rapidly growing rats. In the present study, the experimental animals doubled their body weight; just as for young children, carnitine may be regarded as semiessential for growing animals $(8)$.

Normal carnitine concentrations can be regarded as the tissue carnitine under normal diet. If one defines normal carnitine concentrations as the tissue carnitine occurring with the normal diet, exogenous carnitine is

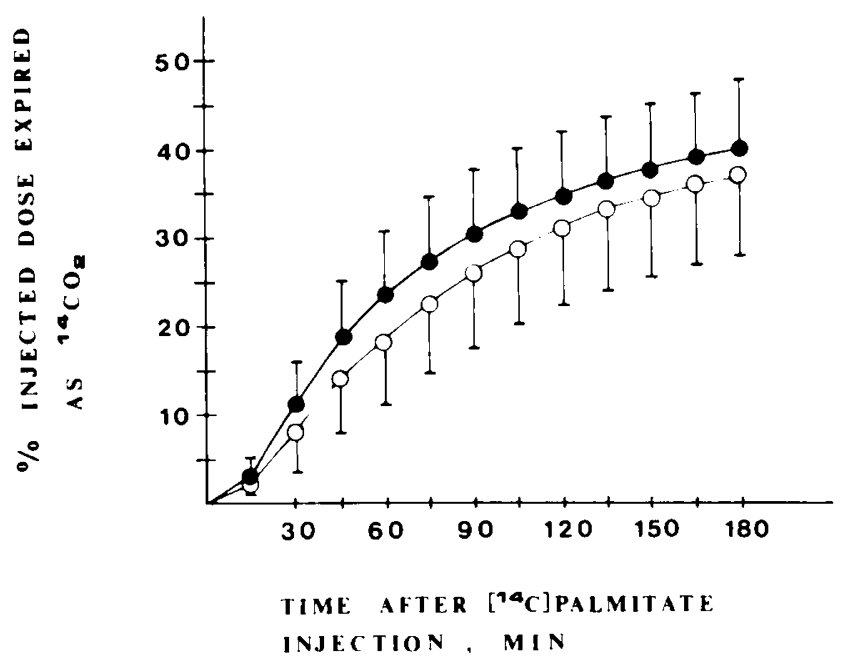

Figure 1. Cumulative $\left[1{ }^{14} \mathrm{C}\right]$ palmitate oxidation in carnitine-depleted rats compared with pair-fed controls. Each point indicates the mean \pm $\mathrm{SD}$ value of the percentage of active $\mathrm{CO}_{2}$ in expired air at a given time point. There was no statistical difference between the groups. $\bullet$ Carnitine-depleted rats $(n=10)$; $O$, pair-fed controls $(n=10)$. necessary to maintain these levels. However, a precise requirement for any age group cannot be stated, because dose-response studies have not been done (8). We have previously studied tissue carnitine concentrations in rats in response to various levels of standard laboratory diet and thereby established the normal carnitine concentrations corresponding to a given amount of food intake (20, 22). In the present study, tissue carnitine concentrations were depleted by $48 \%$ to these normal values.

Despite similar protein contents of the two diets, differences in the amino acid composition might have contributed to the carnitine concentrations. Reduced carnitine concentrations due to insufficient amino acid intake in the carnitine-free diet group are unlikely, because the amounts of the carnitine precursor amino acids lysine and methionine were 1.7 and 3.8 times higher in the experimental carnitine-free diet. It is therefore reasonable to assume that the decreased carnitine concentration in group $I$ reflects insufficient capacity of endogenous carnitine synthesis to compensate for the lack of dietary carnitine.

Theoretically, oxidation of $\left[1-{ }^{14} \mathrm{C}\right]$ palmitate offers a good estimate of whole-body fat oxidation. We found unsatisfactory reproducibility of ${ }^{14} \mathrm{C}$-palmitate oxidation due to insufficient trapping of ${ }^{14} \mathrm{CO}_{2}$-palmitate when previously published methods were applied in pilot studies. Improved trapping efficiency and the use of a scintillation counting solution with specific affinity for $\mathrm{CO}_{2}$ resulted in higher rates of ${ }^{14} \mathrm{C}$-palmitate oxidation than previously reported; nearly $40 \%$ of the total injected activity was trapped versus $2.5-15 \%$ as reported earlier $(28,29)$. Despite these improvements in methodology, there was no difference in the cumulative oxidation of palmitate in $3 \mathrm{~h}$ between the carnitine-depleted rats and their pair-fed controls. Some active palmitate may be lost if it is used, e.g. for lipid synthesis, and therefore not creating active $\mathrm{CO}_{2}$. However, we used the conditions favoring fat oxidation (8-h fast) and a collecting system that was optimized for trapping $\mathrm{CO}_{2}$. We believe the high trapping values of ${ }^{14} \mathrm{CO}_{2}$ reflect the fact that most of the injected palmitate was directed to fat oxidation and also reflect the high metabolic rate in the small animals.

Our carnitine depletion model induced the major reduction of carnitine in skeletal muscle, where most fatty acid oxidation, the main function of carnitine, takes place under the conditions studied. However, our model provides only limited information on the consequences of carnitine depletion in the liver, where a fasting test and the determination of ketone bodies, glucose, and FFA in blood had been more informative. All established experimental methods for the measurement of exercise capacity are hampered by wide individual variations. Exercise capacity could alternatively have been measured by treadmill; we chose swimming as the exercise, because our pilot study and recent work by Musch et al. (30) suggest that exercise capacity in rats measured by running on treadmill is variable and not reproducible enough. On a treadmill, it is also difficult to achieve running to exhaustion by moderate oxygen uptake. Despite strict control of the exercise conditions, considerable variation was 
still present. Lipids are the most important substrate source after 1-2 $\mathrm{h}$ of exercise at $50-60 \%$ of maximal oxygen uptake (31). Accordingly, our model represents moderate metabolic stress (32), where lipid oxidation is the predominant energy source. Any major interference of carnitine depletion with lipid oxidation is likely to reduce the exercise capacity. Because substrate oxidation was not measured during the exercise, the normal exercise capacity is an indirect argument for intact lipid oxidation. An alternative explanation is that if any reduction in lipid oxidation did occur this was compensated by other substrates.

The time to fatigue for a given submaximal work load is also dependent on the initial tissue glycogen concentration at the onset of exercise (33), the mode, intensity, and duration of work, the involvement of different muscle groups, the recruitment pattern of fiber types, and physical fitness (31). We assume that the glycogen stores were similar because pair-feeding was performed. The swimming time to exhaustion was clearly more than $2 \mathrm{~h}$ in each case, and hence fatty acid oxidation was obviously the main energy source during the exercise. Because differences in substrate oxidation during exercise were not studied, it is possible that the relative contribution of carbohydrates and fat to the energy expenditure was different. Even if that is the case, the possible change in substrate utilization during exercise did not limit the exercise capacity. The similar mean swimming times in both groups support the view that carnitine depletion had no major effect on exercise capacity.

Carnitine supplementation improves nitrogen balance during experimental TPN $(6,7)$. We speculated that if carnitine depletion causes reduction of nitrogen retention this might also interfere with exercise capacity, but no effect of carnitine depletion on nitrogen balance was observed.

Moderately decreased tissue carnitine concentrations as a secondary phenomenon have been found in many metabolic disorders $(9,15-17,21)$. The clinical importance of reduced tissue concentrations of carnitine in vivo has not been established, and the physiologic consequences of carnitine deficiency are poorly understood (19). In our experimental model, we reduced tissue carnitine concentrations to levels that are comparable to those in patients with secondary carnitine deficiency (21). The reduction of tissue carnitine of $48 \%$ had no effect on palmitate oxidation, exercise capacity, and nitrogen balance in rats. Normalization or even supranormal tissue concentrations with carnitine supplementation under the same experimental conditions induce no change in fat oxidation (34). The results indicate that wide variations of tissue carnitine concentrations can occur without any major physiologic consequences.

Acknowledgments. The authors thank Huhtamäki OY Leiras, Turku, Finland, for preparing and supplying the TPN solutions, Professor Sven Lindstedt for critical reading of the manuscript, and Professor Kent Lundholm for providing the nitrogen analysis.

\section{REFERENCES}

1. Fritz IB 1963 Carnitine and its role in fatty acid metabolism. Adv Lipid Res $1: 285-3.34$

2. Stumpf DA, Parker WD, Angelini C 1985 Carnitine deficiency, organic acidemias, and Reye's syndrome. Neurology 35:1(141-1045

3. McGarry JD, Robles-Valdes C. Foster DW 1975 Role of carnitine in hepatic ketogenesis. Proc Natl Acad Sci USA 72:4385-4388

4. Felig P, Wahren J 1975 Fuel homeostasis in exercise. N Engl J Med 293:10781084

5. Paul H, Adibi A 1978 Effect of carnitine on branched-chain amino acid oxidation by liver and skeletal muscle. Am J Physiol 234:E494-E499

6. Böles H, Segerer H, Fekl W 1984 Improved N-retention during L-carnitinesupplemented total parenteral nutrition. J Parenter Enteral Nutr 8:9-13

7. Tao RC, Peck GK, Yoshimura N 1981 Effect of carnitine on liver fat and nitrogen balance in intravenously fed growing rats. J Nutr 111:171-177

8. Rebouche CJ 1992 Carnitine function and requirements during the life cycle. FASEB J 6:3379-3386

9. Treem WR, Stanley CA, Finegold DN, Hale DE, Coates PM 1988 Primary carnitine deficiency due to a failure of carnitine transport in kidney, muscle, and fibroblasts. N Engl J Med 319:1331-1336

10. Eriksson BO, Gustafson B, Lindstedt S, Nordin I 1989 Transport of carnitine into cells in hereditary carnitine deficiency. J Inherit Metab Dis 12:108-111

11. Tein I, DeVivo DC, Bierman F, Pulver P, De Meirleir LJ, Cvitanovicsojat L, Pagon RA, Bertini E, Dionisi-Vici C. Servidei S, DiMauro S 1990 Impaired skin fibroblast carnitine uptake in primary systemic carnitine deficiency manifested by childhood carnitine-responsive cardiomyopathy. Pediatr Res 28:247-255

12. Stanley CA, DeLeeuw S, Coates PM 1991 Chronic cardiomyopathy and weakness or acute coma in children with a defect in carnitine uptake. Ann Neurol 30:7(109-716

13. Engel AG, Angelini C 1973 Carnitine deficiency of human skeletal muscle with associated lipid myopathy: a new syndrome. Science 179:899-902

14. Cederblad G, Bylund A-C, Holm J, Schersten T 1976 Carnitine concentration in relation to enzyme activities and substrate utilization in human skeletal muscle. Scand J Clin Lab Invest 36:547-552

15. Rebouche CJ, Engel AG 1983 Carnitine metabolism and deficiency syndromes. Mayo Clinic Proc 58:533-540

16. Chalmers RA, Roe CR, Stacey TE, Hoppel CL 1984 Urinary excretion of t.-carnitine and acylcarnitines by patients with disorders of organic acid metabolism: evidence for secondary insufficiency of t-carnitine. Pediatr Res $18: 1325-1328$

17. Stanley CA 1987 New genetic defects in mitochondrial fatty acid oxidation and carnitine deficiency. Adv Pediatr 34:59-88

18. Holme E, Greter J, Jacobson C.E. Lindstedt S, Nordin 1, Kristiansson B, Jodal U 1989 Carnitine deficiency induced by pivampicillin and pivmecillinam therapy. Lancet 2:469-473

19. Editorial 1990 Carnitine deficiency. Lancet 1:631-633

20. Heinonen OJ, Takala J 1991 Experimental carnitine depletion in rats. Clin Nutr 10:91-96

21. Tein I, De Vivo DC, Ranucci D, DiMauro S 1993 Skin fibroblast carnitine uptake in secondary carnitine deficiency disorders. J lnherit Metab Dis 16:135-146

22. Heinonen OJ, Takala J, Kvist M 1991 Effect of food restriction on tissuc carnitine concentration in rats. Clin Nutr 10:85-90

23. McGarry JD, Foster DW 1976 An improved and simplified radioisotopic assay for the determination of free and esterified carnitine. J Lipid Res 17:277-281

24. Cederblad G, Lindstedt $S 1972$ A method for the determination of carnitine in the picomole range. Clin Chim Acta 37:235-243

25. Dawson CA, Horvath SM 1970 Swimming in small laboratory animals. Med Sci Sports 2:51-78

26. Ward MWN, Owens CWI. Rennie MJ 1980 Nitrogen estimation in biological samples by use of chemiluminescence. Clin Chem 26:1336-1339

27. Negrao CE, Ji LL, Schauer JE, Nagle FJ, Lardy HA 1987 Carnitine supplementation and depletion: tissue carnitines and enzymes in fatty acid oxidation. J Appl Physiol 63:315-321

28. Paul H, Adibi A 1979 Paradoxical effects of clofibrate on liver and muscle metabolism in rats. J Clin Invest 64:405-412

29. Basile C, Lacour B, Di Giulio S, Drueke T 1985 Effect of oral carnitine supplementation on disturbances of lipid metabolism in the uremic rat. Nephron 39:50-54

30. Musch TI, Moore RL, Riedy M, Burke P, Zelis R, Leo ME, Bruno A. Bradford GE 1988 Glycogen concentrations and endurance capacity of rats with chronic heart failure. J Appl Physiol 64:1153-1159

31. Essén B 1977 Intramuscular substrate utilization during prolonged exercise. Ann NY Acad Sci 301:30-44

32. Armstrong RB, Saubert CW, Sembrowich WL, Shepherd RE, Gollnick PD 1974 Glycogen depletion in rat skeletal muscle fibers at different intensities and durations of exercise. Pflugers Arch 352:243-256

33. Bergström J, Hermansen L, Hultman E, Saltin B 1967 Diet, muscle glycogen and physical performance. Acta Physiol Scand 71:140-150

34. Heinonen OJ, Takala J, Kvist MH 1992 Effect of carnitine loading on longchain fatty acid oxidation, maximal exercise capacity, and nitrogen balance. Eur J Appl Physiol 65:13-17 